\title{
Thermal stability and flammability of nanocomposites made of diene rubbers and modified halloysite nanotubes
}

\author{
Przemysław Rybiński • Grażyna Janowska
}

Received: 1 October 2012/Accepted: 4 February 2013/Published online: 26 March 2013

(C) The Author(s) 2013. This article is published with open access at Springerlink.com

\begin{abstract}
This paper presents a method of modification of halloysite with the use of aqueous solutions of halogens and an alcoholic solution of boric acid. The effect of modified nanoadditives on the thermal properties, flammability, and fire hazard of peroxide and sulfur vulcanizates of butadiene-acrylonitrile (NBR) and butadienestyrene (SBR) rubbers was described and assessed. The test results obtained by spectrometric methods, oxygen index, and cone calorimeter were interpreted from the point of view of the chemical structure of the investigated diene elastomers and the particular method of halloysite modification. The analysis of values obtained by the method of cone calorimetry it confirms that most NBR and SBR vulcanizates filled with modified halloysite are more resistant to fire when compared with material without modification. In addition, the modified halloysite are crucial in making self-extinguishing elastomeric materials.
\end{abstract}

Keywords Halloysite nanotubes - Nitrile rubbers ·

Butadiene-styrene rubber · Thermal stability .

Flammability · Fire hazard

\section{Introduction}

In recent years, one has observed a great interest in polymeric materials with special properties, resistant to both

\section{P. Rybiński ( $\square)$}

Management of Environment Protection and Modeling,

The Jan Kochanowski University, Kielce, Poland

e-mail: przemyslaw.rybinski@ujk.edu.pl

G. Janowska

Institute of Polymer and Dye Technology, Technical University

of Łódź, Lodz, Poland considerably lowered and increased temperatures, flameretardant, with appropriate mechanical strength. The problem of polymer flammability reduction or making polymers non-flammable acquires paramount importance due to serious health and life hazards as well as environmental pollution caused by the emission of large amounts of smoke and thermal decomposition and combustion products. Huge amounts of heat emitted during fires frequently cause big material losses.

The substantial improvement in the resistance of polymers to fire could be made by combining them with flameretardant compounds to obtain composites, properties of which constitute the positive features of their components $[1,2]$. The flame-retardant compounds used in the polymer technology, despite their great fire extinguishing capabilities, are characterized by several drawbacks. First of all, when added to the polymer matrix in amounts of 20-50 parts by wt, they often show insufficient compatibility with the polymer involved, and considerably affect processing parameters. On the other hand, the decomposition products of flame-retardant compounds, especially halogens, are strongly corrosive and toxic.

The intensive development of material engineering in recent years has been connected with making a new group of polymeric materials such as polymeric nanocomposites. The decrease in the size of particles incorporated into the polymeric matrix from micrometers to nanometers makes it possible to obtain composites with better, frequently quite new, unique properties [3, 4].

More and more frequently, the nanofillers used in the technology of elastomer's processing consist of halloysite nanotubes.

Halloysite is a naturally occurring aluminosilicate nanotube and the application of this material in rubber composites is very still largely unexplored. Halloysite nanotube (HNT) 
is two-layered aluminosilicate, with a predominantly hollow tubular structure in the submicron range and chemically similar to kaolin. Mismatch in the two-layered alignment of the tetrahedral sheet of silica bonded to the octahedral or gibbsite sheet of alumina causes the wall to curve into cylindrical shape. Intercalated water may occur between the repetitive two-layered sheets comprising the spiral wall, which tends to be irreversibly removed on drying. Halloysite is an economically viable material that can be mined from the consequent deposit as a raw mineral. As for most natural materials, the size of halloysite particles varies within $1-15 \mu \mathrm{m}$ of length and $10-150 \mathrm{~nm}$ of inner diameter, depending on the deposits. Due to its high aspect ratio $(L / D)$, it gives a large amount of filler-polymer interactions compared to other nanofillers [3-8].

The relevant literature review follows that an activated halloysite incorporated into polymeric composites considerably improves their thermal properties and reduces their flammability [9-12].

This paper presents the findings, unreported yet in the literature, concerning the effect of halloysite modified with aqueous solutions of iodine or bromine and an alcoholic solution of boric acid, on the thermal stability, flammability, and fire hazard of diene rubber nanocomposites.

\section{Experimental}

\section{Materials}

We examined the following diene rubbers: Butadieneacrylonitrile rubber, NBR $2255 \mathrm{~V}$, containing $22 \%$ of combined acrylonitrle from Bayer and butadiene-styrene rubber, KER 1500, containing $23.5 \%$ of combined styrene, from Synthos S.A.

The rubbers were cross-linked by means of dicumyl peroxide (DCP) in the presence of zinc oxide $(\mathrm{ZnO})$ or with the use of sulfur in the presence of $\mathrm{ZnO}$ and $\mathrm{N}$-cyclohexyl2-benzoyl sulfenamide (Tioheksam CBS).

Halloysite $(\mathrm{H})$, derived from the Dunino deposit near Legnica (Poland), after its activation by alkali solution [13], was modified with saturated aqueous iodine or bromine (HI, $\mathrm{HBr}$ ) solutions and a saturated alcoholic solution of boric acid (HK) for $24 \mathrm{~h}$ followed by drying to a constant weight [14].

The modified $\mathrm{H}$ was incorporated into rubbers crosslinked with DCP (NN, SN) in a quantity of $5 \mathrm{phr}$ and in the case of rubbers cross-linked with sulfur (NS, SS), in a quantity of 5,8 , or $15 \mathrm{phr}$ per $100 \mathrm{phr}$ of elastomer (Table 1). The peroxide and sulfur vulcanizates of investigated rubbers containing $\mathrm{H}$ in a quantity of $5 \mathrm{phr}$, constituting reference samples were denoted with symbols NNH5, SNH5 and NSH5, SSH5, respectively (Table 1).
Methods

The photographs of modified $\mathrm{H}$ and composites were taken by the SEM Quanta 250 FEG microscope.

The fracture of rubber/HNTs composites have been obtained by plunge composites in liquid nitrogen. Before observation in microscope, the samples were coated in with gold.

The size of $\mathrm{H}$ particles was determined by the ZetaSizer Nano Series S90 (Malvern Instruments).

The measurements of wide-angle scattering of X-radiation (WAXS) in the modified $\mathrm{H}$ and $\mathrm{H}$-containing nanocomposites were performed at room temperature using an $\mathrm{X}$-ray apparatus from Phillips (X-Ray source operating at: $U=30 \mathrm{kV}$ and $I=50 \mathrm{~mA}$. Wavelength $=0.15418 \mathrm{~nm})$ at the Center of Molecular and Macromolecular Studies, the Polish Academy of Science, in Lodz. Diffraction patterns were recorded within the angle range $2 \theta=1 \div 35^{\circ}$; measurement step $0.05^{\circ}$; measurement time $25 \mathrm{~s}$, radiation $\mathrm{CuK} \alpha(\lambda=0.15418 \mathrm{~nm})$, operation in transmission mode. The apparatus was calibrated at the beginning of each measurement series. The samples of the nanocomposites tested were disintegrated before analysis by the CAT X520D homogenizer (revolutions 16-30,000), cooled in a liquid nitrogen, transferred onto a polystyrene holder and placed in a disposable measurement ring. The WAXS measurements of tested $\mathrm{H}$ were used as a reference measurement for nanocomposites.

The bromine and iodine contents in the tested nanofillers were determined by the ICP MS TOF OptiMass 9500 spectrometer (GBC) after their mineralization in a microwave mineralizer Magnum II (Ertec).

The IR spectra of unmodified and modified Hs were taken by the BIO-RAD $175 \mathrm{C}$ apparatus with Fourier's transformation, using a $\mathrm{KBr}$ tablet.

Elastomeric blends were prepared at room temperature with the use of a laboratory rolling mill $(D=150 \mathrm{~mm}$, $L=300 \mathrm{~mm}$ ). The rotational speed of the front roll was $20 \mathrm{rpm}$, and friction 1.1.

The blends were vulcanized in steel molds placed between electrically heated press shelves. The optimal vulcanization time $\left(\tau_{0.9}\right)$ at a temperature of $160{ }^{\circ} \mathrm{C}$ was determined by the a WG-2 vulcameter according to the standard PN-ISO 3417:1994.

The thermal properties of vulcanizate were tested under air within the temperature range of $25-800{ }^{\circ} \mathrm{C}$ by the MOM derivatograph (Budapest), using $\mathrm{Al}_{2} \mathrm{O}_{3}$ as reference substance. Weighed portions were $90 \mathrm{mg}$ each with, heating rate of $7.9^{\circ} \mathrm{C} \mathrm{min}{ }^{-1}$, and the sensitivities of thermal curves as follows: $T G=100, D T A=1 / 5, D T G 1 / 30$.

The flammability of vulcanizates was determined by the oxygen index method, using an apparatus from Fire Testing Technology Ltd and $50 \times 10 \times 4 \mathrm{~mm}$ specimens. With a 
Table 1 Sample nomenclature

\begin{tabular}{ll}
\hline Sample & Sample nomenclature \\
\hline NN & Peroxide vulcanizate of NBR rubber \\
NS & Sulfur vulcanizate of NBR rubber \\
SN & Peroxide vulcanizate of SBR rubber \\
SS & Sulfur vulcanizate of SBR rubber \\
NNH5 & Peroxide vulcanizate of NBR rubber containing halloysite in a quantity of 5 phr \\
NSH5, NSH8, NSH15 & Sulfur vulcanizate of NBR rubber containing halloysite in a quantity of 5, 8, 15 phr \\
SNH5 & Peroxide vulcanizate of SBR rubber containing halloysite in a quantity of 5 phr \\
SSH5, NSH8, NSH15 & Sulfur vulcanizate of SBR rubber containing halloysite in a quantity of 5, 8, 15 phr \\
HI & Halloysite modified by iodine \\
HBr & Halloysite modified by bromine \\
HK & Halloysite modified by boric acid \\
\hline
\end{tabular}

constant nitrogen flow rate through a measurement column $(\emptyset=75 \mathrm{~mm})$, amounting to $40 \pm 2 \mathrm{~mm} \times \mathrm{s}^{-1}$, the oxygen concentration was selected the way that the sample was completely burned within time $t=180 \mathrm{~s}$. The sample top was ignited for $5 \mathrm{~s}$ by the gas burner supplied with LPG $[11,13,15]$.

We also tested flammability in air using identical samples as in the case of OI method. A sample in a vertical position was ignited with a gaseous burner for $5 \mathrm{~s}$ and its combustion time $\left(t_{\mathrm{s}}\right)$ was measured.

The vulcanizates under investigation were examined by the FAA microcalorimeter from Fire Testing Technology Limited, with a constants flow ratio oxygen to nitrogen amounting 1:4. The temperature of pyrolyser was $750{ }^{\circ} \mathrm{C}$, while that of combustor $900{ }^{\circ} \mathrm{C}$. During measurement, the following parameters were recorded: ignition temperature, maximal heat emission rate, temperature of maximal heat emission rate, total heat emitted, heat capacity (HR), and percentage oxygen consumption. Samples were tested also under conditions of real fire with the use of a cone calorimeter from Fire Testing Technology Limited. Elastomer samples with dimensions $(100 \times 100 \pm 1) \mathrm{mm}$ and a thickness of $(2 \pm 0.5) \mathrm{mm}$ were tested in a horizontal position, with a density of heat radiation flux amounting to $35 \mathrm{~kW} \times \mathrm{m}^{-2}$. During testing, the following parameters were recorded: initial sample weight, time to ignition (TTI), sample weight during testing, total heat released (THR), effective heat of combustion (EHC), average mass loss rate (MLR), heat release rate (HRR), final sample weight and time to extinguish, and test duration.

\section{Results and discussion}

The alkaline activation of $\mathrm{H}$ was aimed at the exposure of HNTs through the removal of higher aluminosilicate acids from their surface and space between them (Table 2) [13].
Based on the photographs taken by means of an electron microscope, it has been found that the modification (iodine or bromine solution) of the filler used does not adversely affect its structure. Despite the use of aggressive modifying solutions, HNTs remain visible in the images obtained (Fig. 1). The size of HNTs before and after its modification by bromine or iodine solution are presented in Table 2 .

Figure 2 compares the X-ray diffraction spectra of halloysite nanotubes (HNTs) activated by alkali solution and NNH5, NSH5 nanocomposites.

The basal space reflections of HNTs indicate a sharp peak at $2 \theta=12.27^{\circ}$, corresponding to a (001) basal spacing of $0.7 \pm 0.3 \mathrm{~nm} \mathrm{[3].}$

However, in the NNH5, NSH5 nanocomposites, peak was not detected at $2 \theta=12.27^{\circ}$. It is clear that HNTs in the nanocomposites appeared not to be intercalated by the rubber chains [16].

The morphology of the rubber/HNTs composites are showed on the Fig. 3.

Figure 3 represents the tensile fracture surface of rubber/HNTs hybrid composites at 4,000 $\div 10,000 \times$ magnification. It can be seen that there is a good adhesion between HNTs and elastomer matrix. It can be seen that the dispersion of HNTs in the rubber matrix is not very well because the aggregates of HNTs with different sizes are observed (Fig. 3a, b).

The test results obtained by the ICP MS TOF method show that the iodine content in the modified $\mathrm{H}$ is $8.45 \%$ and that content of bromine amounts to $10.21 \%$.

The modification of $\mathrm{H}$ with aqueous solutions of halogens or an alcoholic solution of boric acid causes significant changes in the IR spectra, what is shown on Fig. 4.

Changes in the intensity and position of characteristic signals of internal hydroxyl groups bounded with the surface of $\mathrm{H}$ indicate that some hydrogen bonds in the $\mathrm{H}$ structure are broken while new bonds are formed at the same time. A broad signal within the range of $3,300-3,500 \mathrm{~cm}^{-1}$, 
Table 2 The size of HNTs before and after its modification

\begin{tabular}{|c|c|c|c|c|c|c|c|}
\hline \multicolumn{2}{|l|}{ HNTs } & \multicolumn{2}{|c|}{$\begin{array}{l}\text { HNTs modified by alkali } \\
\text { solution }\end{array}$} & \multicolumn{2}{|c|}{$\begin{array}{l}\text { HNTs modified by alkali } \\
\text { and } \mathrm{HBr} \text { solution }\end{array}$} & \multicolumn{2}{|c|}{$\begin{array}{l}\text { HNTs modified by alkali and HI } \\
\text { solution }\end{array}$} \\
\hline Size/nm & Mean intensity $/ \%^{\mathrm{a}}$ & Size/nm & Mean intensity $/ \%^{\mathrm{a}}$ & Size/nm & Mean intensity $/ \%^{\mathrm{a}}$ & Size/nm & Mean intensity $/ \%^{\mathrm{a}}$ \\
\hline 130.8 & 15.3 & 1.591 & 17.7 & 80.7 & 21.3 & 67.2 & 22.1 \\
\hline 146.9 & 22.7 & 1.786 & 19.5 & 102.1 & 14.1 & 90.1 & 15.9 \\
\hline 164.9 & 27.3 & 4.025 & 15.8 & 115.1 & 39.6 & 104.8 & 40.3 \\
\hline 185.2 & 19.5 & 4.520 & 31.3 & 128.0 & 20.7 & 110.1 & 20.0 \\
\hline 208.0 & 15.2 & 5.076 & 15.7 & 135.0 & 4.3 & 120.3 & 1.7 \\
\hline
\end{tabular}

The values highlighted in bold determine a dominant size of halloysite nanotubes

${ }^{a}$ Intensity of HNTs fraction

Fig. 1 a SEM photo of HNTs modified by saturated aqueous iodine (HI). b HNTs modified by saturated aqueous bromine $(\mathrm{HBr})$
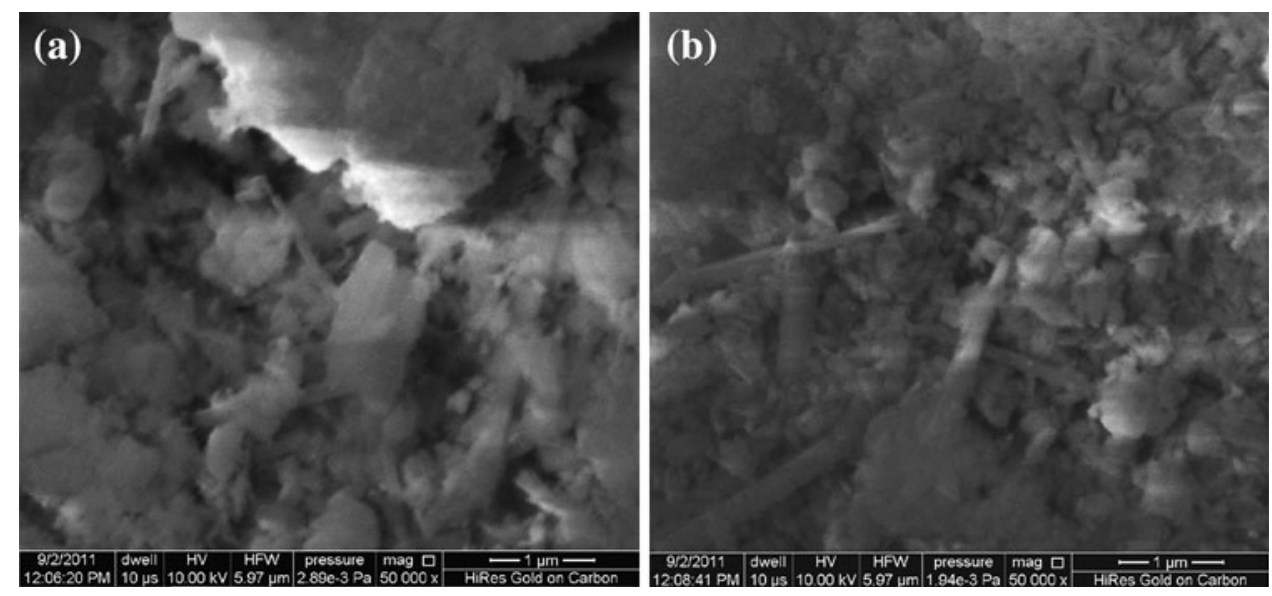

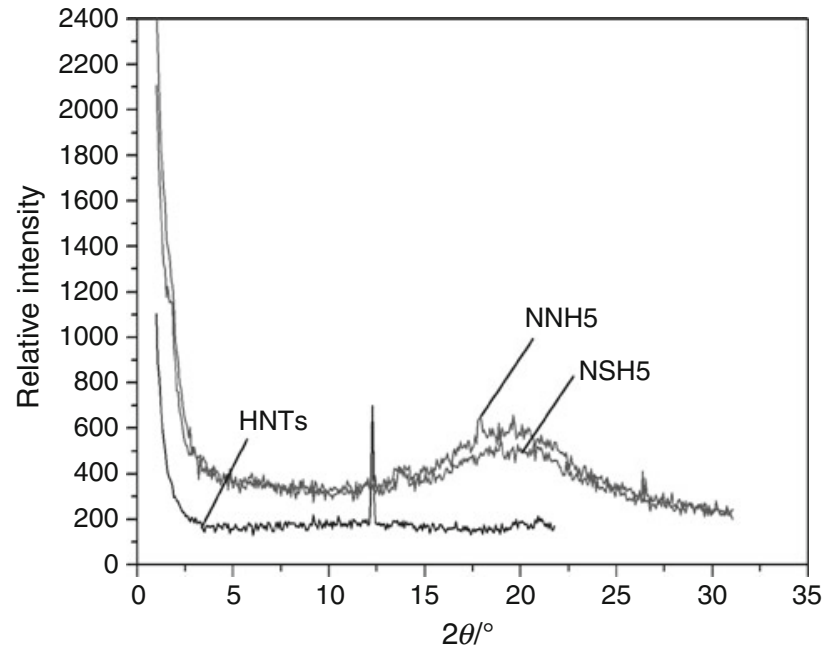

Fig. 2 WAXS pattern of HNTs and the nanocomposites

testifying to the presence of internal hydroxyl groups, is considerably decreased due to the $\mathrm{H}$ modification with the iodine or bromine solution, at the same time, the intensity of signals at wave numbers $3621,3696 \mathrm{~cm}^{-1}$ very clearly increases $[6,17]$. The increase in the intensity of these signals can result from iodine or bromine interaction with the internal hydroxyl groups of $\mathrm{H}$ through new hydrogen bonds.
Some changes in the IR spectrum of the modified $\mathrm{H}$ also occur within the wave number range of $1,300-1,700 \mathrm{~cm}^{-1}$.

In the case of the $\mathrm{H}$ modified with aqueous solutions of halogens or alcoholic solution of boron acid, the band at $1,636 \mathrm{~cm}^{-1}$, testifying to the quantity of water chemically bounded with the aluminosilicate surface, is decreased. At the same time, in the case of the $\mathrm{H}$ modified with alcoholic solution of boron acid, the signal at $1,385 \mathrm{~cm}^{-1}$ testifying to the considerable quantity of water physically occluded in the aluminosilicate structure, is very clearly increased. The remaining signals within the range of $460-1,300 \mathrm{~cm}^{-1}$ remain unchanged.

The effect of the modified $\mathrm{H}$ on the thermal properties of NBR and SBR vulcanizates depends on both the chemical structure of elastomer macromolecules and the structure of their spatial network. The analysis of the DTA curves of examined nanocomposites has shown that modified $\mathrm{H}$ does not change the temperature of the first and second exothermic transitions that are connected to a thermal crosslinking of NBR (Figs. 5a, 6a, b) or SBR (Figs. 5b, 6c, d) rubber. However, it exerts a significant influence on the character of the next transition related to the thermal decomposition of nanocomposites (Figs. 5, 6).

The thermal decomposition of the NBR vulcanizate containing unmodified $\mathrm{H}$ results from exothermic processes 
Fig. 3 Morphology of the rubber/HNTs composites
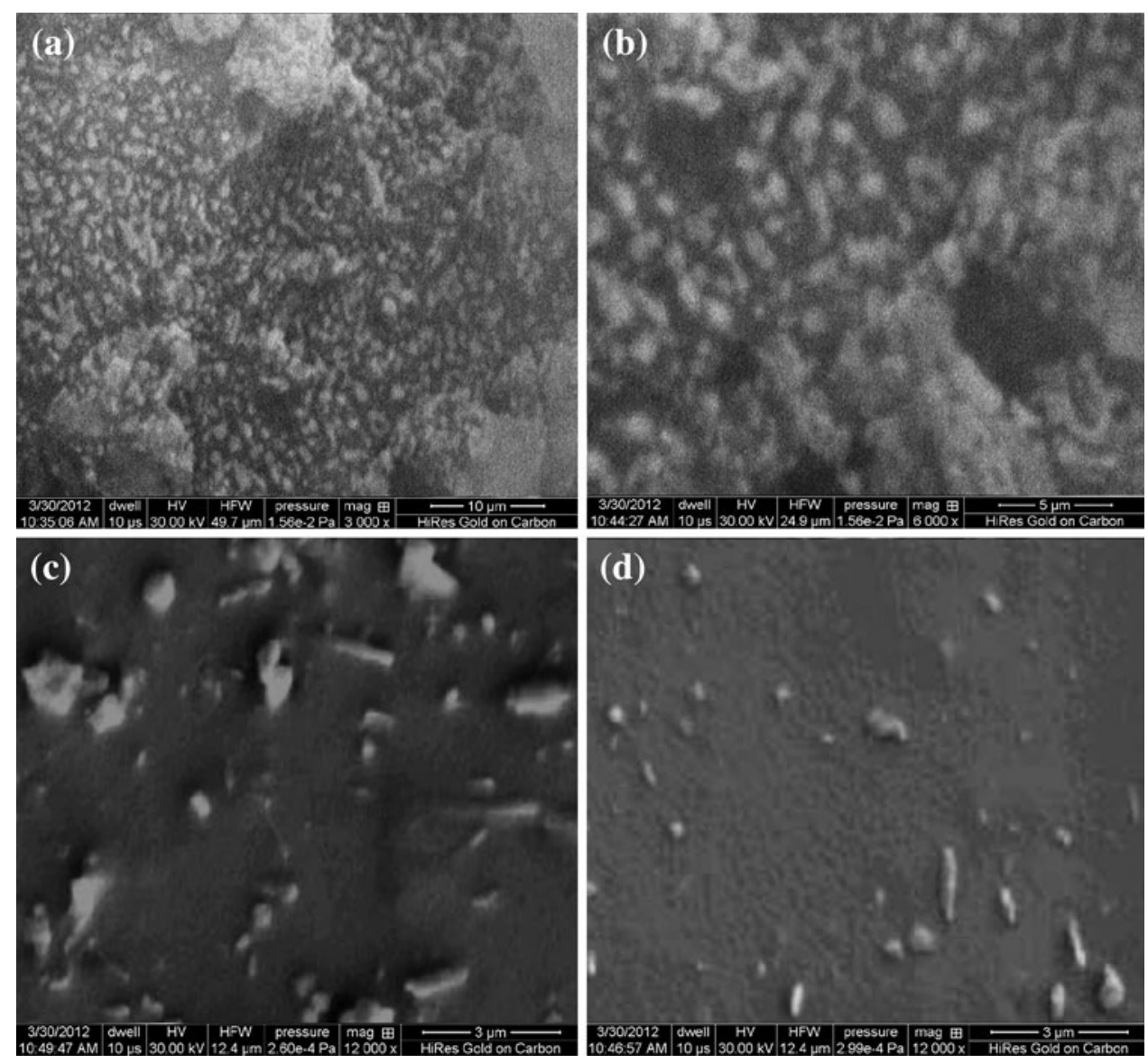

Fig. 4 IR spectra unmodified and modified iodine, bromine, and boron acid halloysite

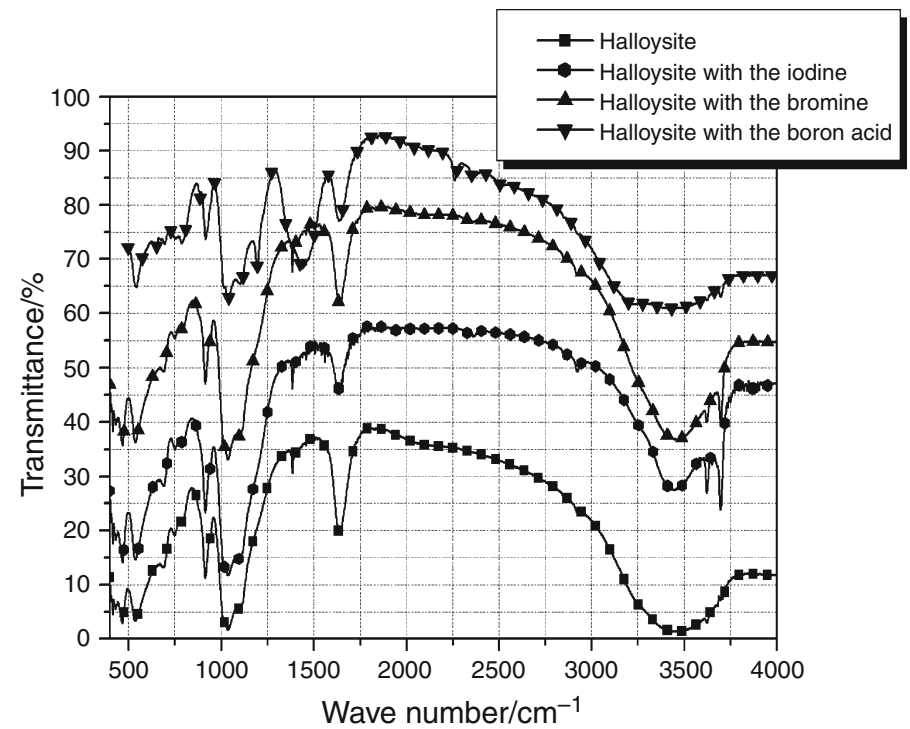

clear decrease in the thermal decomposition rate $(\mathrm{d} m / \mathrm{d} t)$ of the NBR vulcanizates filled with the modified $\mathrm{H}$ results from the partially ionic character of the destruction process (Table 3). The decrease in the destruction rate is accompanied by an increase in the residue observed after the termination of this process $(P w)$. This indicates that the halogen
(Fig. 5a). The modified $\mathrm{H}$ changes the character of the destruction of NBR rubber cross-linked, especially with the organic peroxide (Fig. 6a, b), and decreases the rate of this process, shown in Table 3. The decomposition of the SBR vulcanizates containing the modified filler has an endothermic character regardless of the spatial network structure. The 
Fig. 5 Thermal curves

a nanocomposite NNH5,

b nanocomposite NSH5

Fig. 6 DTA curves nanocomposites a peroxide nanocomposites of NBR rubber, b sulfur nanocomposites of NBR rubber, $\mathbf{c}$ peroxide nanocomposites of SBR rubber, d sulfur nanocomposites of SBR rubber (a)

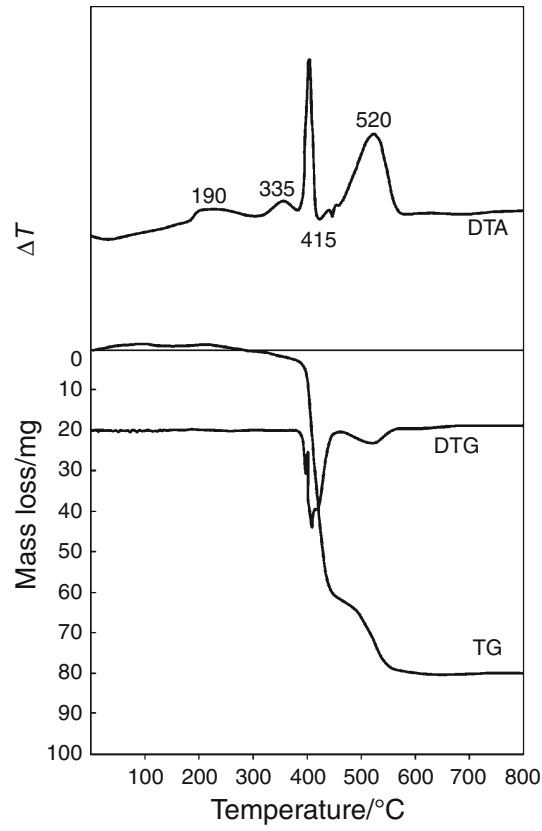

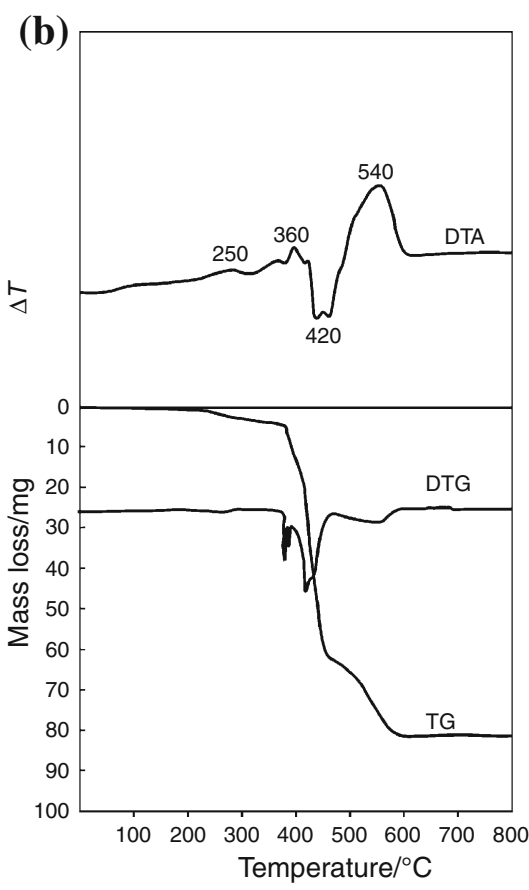
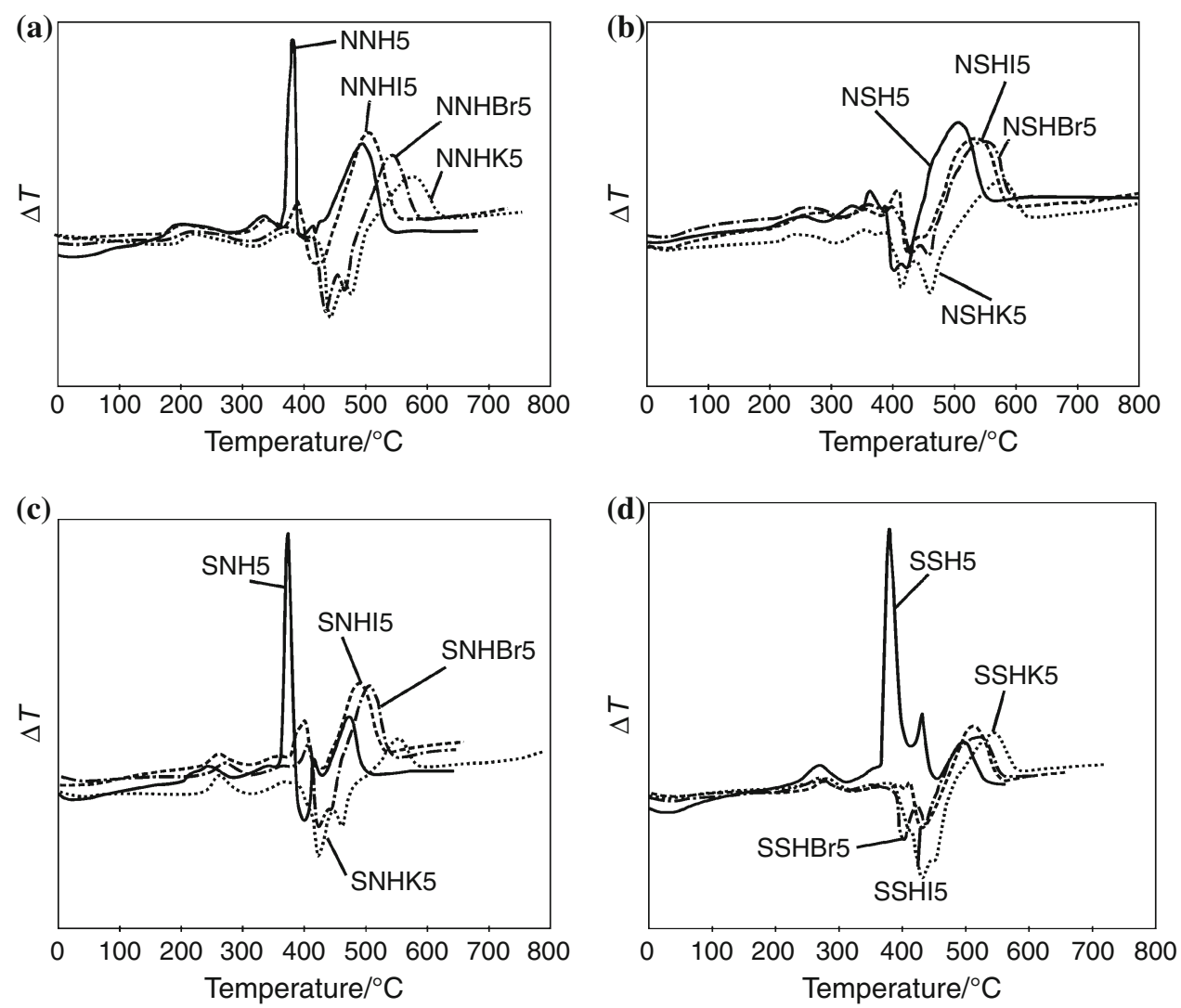

modifiers, chemically combined with the filler surface or occluded in the free spaces of aluminosilicate, facilitate the processes of cyclization or carbonization proceeding during the thermal decomposition of both cross-linked polymers
(Table 3). It should be stressed that the elastomer susceptibility to the formation of solid products of thermal decomposition also depends on physical intermolecular interactions, measure of which is the density of cohesion 
energy. Owing to the higher value of this parameter in the case of NBR copolymer, this rubber shows a greater susceptibility to form a cyclized, carbonized residue $(P w)$ in relation to SBR (Table 3) [18].

It could be concluded that reduced rate of thermal decomposition, with simultaneous cyclization and carbonization during destruction of elastomers, exert a beneficial influence on the reduction in their flammability. A lower quantity of volatile and flammable products passes to flame, while the boundary layer between the solid and gaseous combustion zone show a great thermal stability and impedes the transport of mass and energy during the combustion of polymeric material. It should be clearly stressed that the presence of unmodified $\mathrm{H}$ in the matrix of rubbers also considerably increases their cyclization and carbonization capabilities. A portion of $\mathrm{H}$ in the boundary layer of sample combustion is dehydrated and dehydroxylated, exerting a positive effect on the value of $\mathrm{d} m / \mathrm{d} t$, changing into an amorphous intercalated meta-H (Scheme) [19-22].

$$
\begin{array}{r}
\mathrm{Al}_{2} \mathrm{Si}_{2} \mathrm{O}_{5}(\mathrm{OH})_{4} \times 2 \mathrm{H}_{2} \mathrm{O} \stackrel{200{ }^{\circ} \mathrm{C}}{\longrightarrow} \mathrm{Al}_{2} \mathrm{Si}_{2} \mathrm{O}_{5}(\mathrm{OH})_{4} \\
\stackrel{600-700{ }^{\circ} \mathrm{C}}{\longrightarrow} \mathrm{Al}_{2} \mathrm{Si}_{2} \mathrm{O}_{5}
\end{array}
$$

Scheme 1 Decomposition of halloysite [19]

\begin{tabular}{|c|c|c|c|c|c|c|c|}
\hline Sample & $T_{5} /{ }^{\circ} \mathrm{C}$ & $T_{50} /{ }^{\circ} \mathrm{C}$ & $\mathrm{d} m \times \mathrm{d} t^{-1} / \mathrm{mm}$ & $T_{\text {RMAX }} /{ }^{\circ} \mathrm{C}$ & $P w / \%$ & $t_{\mathrm{s}} /{ }^{\circ} \mathrm{C}$ & $P_{800} / \%$ \\
\hline NNH5 & 390 & 420 & 57 & 410 & 24.5 & 510 & 11.1 \\
\hline NNHI5 & 350 & 420 & 47 & 405 & 31.1 & 480 & 8.8 \\
\hline NNHBr5 & 350 & 420 & 53 & 400 & 31.1 & 480 & 10 \\
\hline NNHK5 & 360 & 420 & 50 & 400 & 31.1 & 490 & 8.8 \\
\hline NSH5 & 360 & 410 & 76 & 400 & 20 & 480 & 7 \\
\hline NSHI5 & 295 & 400 & 45 & 390 & 30 & 480 & 11.1 \\
\hline NSHI8 & 340 & 410 & 43 & 400 & 36.7 & 490 & 15.6 \\
\hline NSHI15 & 320 & 415 & 39 & 390 & 38.9 & 480 & 18.9 \\
\hline NSHBr5 & 305 & 410 & 47 & 400 & 32.2 & 495 & 10.0 \\
\hline NSHBr8 & 320 & 415 & 45 & 400 & 36.7 & 485 & 15.5 \\
\hline NSHBr15 & 290 & 420 & 43 & 400 & 38.9 & 470 & 16.7 \\
\hline NSHK5 & 300 & 405 & 45 & 390 & 33.4 & 500 & 12.2 \\
\hline NSHK8 & 260 & 400 & 36 & 390 & 27.8 & 480 & 8.8 \\
\hline NSHK15 & 320 & 405 & 39 & 390 & 38.9 & 490 & 18.9 \\
\hline SNH5 [13] & 335 & 415 & 50 & 405 & 22.2 & 500 & 10.5 \\
\hline SNHI5 & 370 & 420 & 56 & 400 & 25.5 & 480 & 11.1 \\
\hline SNHBr5 & 360 & 415 & 60 & 400 & 24.0 & 480 & 11.1 \\
\hline SNHK5 & 280 & 410 & 56 & 400 & 21.1 & 495 & 10 \\
\hline SSH5 [13] & 305 & 405 & 50 & 370 & 27.2 & 505 & 11.1 \\
\hline SSHI5 & 280 & 400 & 52 & 390 & 26.7 & 470 & 11.1 \\
\hline SSHI8 & 305 & 405 & 50 & 390 & 31.1 & 470 & 14.5 \\
\hline SSHI15 & 270 & 390 & 43 & 385 & 36.7 & 470 & 18.9 \\
\hline SSHBr5 & 240 & 390 & 53 & 380 & 24.5 & 470 & 10 \\
\hline SSHBr8 & 265 & 400 & 50 & 385 & 25.5 & 480 & 14.5 \\
\hline SSHBr15 & 295 & 405 & 45 & 390 & 45 & 480 & 18.9 \\
\hline SSHK5 & 275 & 400 & 43 & 380 & 28 & 490 & 12.2 \\
\hline SSHK8 & 260 & 400 & 40 & 385 & 26.7 & 480 & 12.2 \\
\hline SSHK15 & 250 & 400 & 38 & 385 & 26.6 & 480 & 13.3 \\
\hline
\end{tabular}

Table 3 Thermal analysis nanocomposites of NBR and SBR rubbers

$5,8,15$ parts (in phr.) of filler incorporated to polymer matrix

$T_{5}$ and $T_{50}$-temperature of sample 5 and $50 \%$ mass loss, respectively $\mathrm{d} m \times \mathrm{d} t^{-1}$-maximum rate of thermal decomposition of vulcanizates

$T_{\mathrm{RMAX}}$ temperature of maximum rate of thermal decomposition of vulcanizates, $P w$ residue after the thermal decomposition of vulcanizates, $t_{\mathrm{s}}$ combustion time in air, $P_{800}$ residue after heating up to $T=800{ }^{\circ} \mathrm{C}$ 
Table 4 Flammability test results of nanocomposites obtained by the use of oxygen index and FAA micro-calorimeter

\begin{tabular}{|c|c|c|c|c|c|c|c|c|}
\hline Sample & $O I$ & $t_{\mathrm{s}} / \mathrm{s}$ & $T z /{ }^{\circ} \mathrm{C}$ & $\mathrm{HRR}_{\max } / \mathrm{W} \mathrm{g}^{-1}$ & $\mathrm{TRR}_{\max } /{ }^{\circ} \mathrm{C}$ & $\mathrm{HR} / \mathrm{J} \mathrm{g}^{-1} \mathrm{~K}^{-1}$ & Residue after burning/\% & Oxygen consumption $/ \%$ \\
\hline NNH5 & 0.220 & 336 & 362 & 413 & 460 & 423 & 5.1 & 45.8 \\
\hline NNHI5 & 0.237 & $313^{\mathrm{a}}$ & 368 & 418 & 473 & 449 & 7.6 & 59.9 \\
\hline NNHBr5 & 0.243 & $321^{\mathrm{a}}$ & 366 & 408 & 469 & 469 & 7.7 & 61.6 \\
\hline NNHK5 & 0.240 & 212 & 371 & 413 & 472 & 421 & 7.2 & 56.9 \\
\hline NSH5 & 0.215 & 284 & 357 & 356 & 460 & 353 & 1.3 & 30.9 \\
\hline NSHI5 & 0.230 & $349^{\mathrm{a}}$ & 369 & 370 & 470 & 370 & 12.6 & 49.7 \\
\hline NSHI8 & 0.245 & $435^{\mathrm{a}}$ & 372 & 346 & 471 & 368 & 10.5 & 55.3 \\
\hline NSHI15 & 0.271 & $397^{\mathrm{a}}$ & 371 & 358 & 467 & 361 & 16.1 & 49.1 \\
\hline NSHBr5 & 0.250 & $327^{a}$ & 373 & 355 & 475 & 391 & 8.9 & 58.7 \\
\hline NSHBr8 & 0.245 & $363^{a}$ & 376 & 342 & 473 & 361 & 10.9 & 55.8 \\
\hline NSHBr15 & 0.275 & $431^{\mathrm{b}}$ & 373 & 334 & 470 & 355 & 19.2 & 37.7 \\
\hline NSHK5 & 0.225 & 171 & 370 & 350 & 465 & 381 & 7.2 & 40.3 \\
\hline NSHK8 & 0.247 & 190 & 365 & 340 & 465 & 371 & 9.4 & 41.2 \\
\hline NSHK15 & 0.265 & 223 & 360 & 339 & 467 & 352 & 15.9 & 45.5 \\
\hline SNH5 [13] & 0.225 & 247 & 365 & 431 & 453 & 422 & 11.26 & 41.7 \\
\hline SNHI5 & 0.240 & 220 & 367 & 390 & 466 & 426 & 6.5 & 44.5 \\
\hline SNHBr5 & 0.265 & 205 & 375 & 325 & 470 & 390 & 7.7 & 56.9 \\
\hline SNHK5 & 0.255 & 215 & 367 & 330 & 472 & 472 & 10.1 & 47.1 \\
\hline SSH5 [13] & 0.235 & 405 & 358 & 373 & 460 & 366 & 4.65 & 28.5 \\
\hline SSHI5 & 0.238 & 244 & 374 & 378 & 465 & 396 & 11.1 & 38.8 \\
\hline SSHI8 & 0.245 & 290 & 370 & 369 & 464 & 366 & 10.9 & 37.3 \\
\hline SSHI15 & 0.258 & $453^{\mathrm{a}}$ & 369 & 349 & 467 & 342 & 8.7 & 36.1 \\
\hline SSHBr5 & 0.238 & $452^{\mathrm{a}}$ & 370 & 365 & 464 & 369 & 8.9 & 68.7 \\
\hline SSHBr8 & 0.256 & $451^{\mathrm{a}}$ & 366 & 352 & 465 & 399 & 9.6 & 57.2 \\
\hline SSHBr15 & 0.275 & $467^{\mathrm{a}}$ & 368 & 316 & 467 & 365 & 12.3 & 53.4 \\
\hline SSHK5 & 0.228 & 250 & 364 & 343 & 464 & 345 & 9.8 & 37.6 \\
\hline SSHK8 & 0.235 & 300 & 365 & 366 & 466 & 366 & 10.3 & 48.8 \\
\hline SSHK15 & 0.265 & 313 & 363 & 358 & 465 & 358 & 15.6 & 48.9 \\
\hline
\end{tabular}

$O I$ oxygen index, $T_{\mathrm{s}}$ temperature of residue burning after the thermal decomposition of vulcanizates, $T z$ Ignition temperature, $H R R_{\max }$ maximal heat release rate, $T R R_{\max }$ Temperature of maximal heat release rate, $H R$ Heat release capacity

${ }^{a}$ Self-extinguishing samples

b Samples ignition after $20 \mathrm{~s}$ action of gas burner flame

Meta-H, possessing a lamellar structure as kaolinite or montmorillonite only occurs in the thin layer at the sampleflame interface. The parameter $P_{800}$, which value increases proportionally to the quantity of aluminosilicate incorporated into the rubber matrix, has confirmed the formation of carbonizate after rubber decomposition. In deeper layers of tested nanocomposites, the HNTs dominate and impede the diffusion of liquid destruction products into flame (channeling effect). Also trapping, in their empty spaces, destruction products in liquid form are then cross-linked or cyclized, facilitates the formation of an insulating carbon layer.

Regardless of the chemical structure of the elastomers under investigation, their thermal stability determined with coefficients $T_{5}$ and $T_{50}$ depends on the cross-linking system, and consequently on the spatial network structure (Table 3 ). The greater thermal stability of rubbers cross- linked with the organic peroxide results from the higher energy of $\mathrm{C}-\mathrm{C}$ bonds when compared with that of sulfide bonds.

The presence of the $\mathrm{H}$ modified with the aqueous solution of iodine or bromine and the alcoholic solution of boric acid, clearly influences the thermal stability of the investigated nanocomposites Table 3. Regardless of the chemical structure of macromolecules and the structure of their spatial network, the modified $\mathrm{H}$ causes a decrease in the thermal stability of cross-linked elastomers, especially that determined with $T_{5}$ (Table 3 ). In addition, the initial weight loss stage of nanocomposites is caused by the release of hydrogen halides or water vapor, which decreases the value of $T_{5}$, but it causes a considerable increase ignition temperature $(T z)$ in most polymeric materials tested (Tables 3, 4). 
Table 5 Flammability test results of nanocomposites obtained by the use of cone calorimeter

\begin{tabular}{|c|c|c|c|c|c|c|c|}
\hline Sample & $\mathrm{TTI} / \mathrm{s}$ & $\mathrm{THR} / \mathrm{MJ} \mathrm{m}^{-2}$ & $\mathrm{HRR} / \mathrm{kW} \mathrm{m}^{-2}$ & $\mathrm{EHC} / \mathrm{MJ} \mathrm{kg}^{-1}$ & $\mathrm{EHC}_{\max } / \mathrm{MJ} \mathrm{kg}^{-1}$ & $\begin{array}{l}\text { Percentage } \\
\text { mass lost } / \%\end{array}$ & MLR/g m ${ }^{-2} \mathrm{~s}^{-1}$ \\
\hline NNH5 & 60 & 33.1 & 192.2 & 20.2 & 75.1 & 94.7 & 28.9 \\
\hline NNHI5 & 67 & 23.5 & 147.8 & 15.1 & 63.4 & 86.8 & 28.1 \\
\hline NNHBr5 & 70 & 20.4 & 157.4 & 14.2 & 70.6 & 92.1 & 21.5 \\
\hline NNHK5 & 69 & 24.3 & 153.5 & 16.1 & 61.2 & 85.5 & 24.3 \\
\hline NSH5 & 58 & 27.6 & 195.8 & 17.5 & 72.6 & 87.1 & 28.8 \\
\hline NSHI5 & 65 & 27.5 & 194.1 & 18.1 & 69.7 & 87.3 & 21.8 \\
\hline NSHI8 & 63 & 26.4 & 180.8 & 15.0 & 70.4 & 85.9 & 24.2 \\
\hline NSHI15 & 60 & 27.6 & 193.6 & 17.5 & 68.1 & 85.2 & 21.3 \\
\hline NSHBr5 & 65 & 24.0 & 154.1 & 18.1 & 75.2 & 89.6 & 18.2 \\
\hline NSHBr8 & 80 & 24.2 & 108 & 15.9 & 79.6 & 90.1 & 24.4 \\
\hline NSHBr15 & 70 & 25.7 & 152 & 16.1 & 68.7 & 83.0 & 20.5 \\
\hline NSHK5 & 71 & 25.2 & 184 & 16.1 & 75.1 & 92.3 & 27.9 \\
\hline NSHK8 & 58 & 24.3 & 215 & 15.8 & 63.8 & 88.7 & 23.9 \\
\hline NSHK15 & 55 & 25.7 & 120.7 & 18.4 & 79.9 & 78.7 & 14.1 \\
\hline SNH5 & 58 & 24.2 & 169 & 16.9 & 79.4 & 91.0 & 19.1 \\
\hline SNHI5 & 54 & 29.1 & 100.1 & 19.8 & 79.4 & 91.1 & 23.5 \\
\hline SNHBr5 & 67 & 21.9 & 119.3 & 15.5 & 78.3 & 87.6 & 21 \\
\hline SSH5 & 47 & 28.1 & 190.2 & 16.9 & 74.2 & 91.3 & 27.6 \\
\hline SSHI5 & 65 & 25.8 & 164.8 & 18.3 & 79.1 & 81.1 & 20.3 \\
\hline SSHI8 & 64 & 25.3 & 154.3 & 17.5 & 74.2 & 85.9 & 23.1 \\
\hline SSHI15 & 64 & 24.8 & 157 & 16.6 & 71.9 & 81.6 & 21.6 \\
\hline SSHBr5 & 67 & 26.2 & 168.1 & 17.6 & 68.9 & 89.6 & 26.6 \\
\hline SSHBr8 & 67 & 25.6 & 145.9 & 17.6 & 76.6 & 86.1 & 21.3 \\
\hline SSHBr15 & 68 & 19.3 & 137.9 & 14.4 & 69.5 & 82.3 & 19.6 \\
\hline SSHK5 & 57 & 28.7 & 106.5 & 19.9 & 79.9 & 83.7 & 17.7 \\
\hline
\end{tabular}

$T T I$ time to ignition, $T H R$ total heat release, $H R R$ heat release rate, $E H C$ effective heat of combustion, $E H C_{\max }$ max effective heat of combustion, $M L R$ average specific mass lost rate

The analysis of results from flammability tests indicates that regardless of the chemical structure of polymer and its spatial network structure, the modified $\mathrm{H}$ decreases the flammability of the nanocomposites, which was determined with the value of oxygen index (OI, Table 4). The $O I$ value of vulcanizates increases with increasing the filler content. The greatest reduction in flammability in terms of this index occurs in the case of the vulcanizates of both rubbers filled with $\mathrm{H}$ modified with the aqueous solution of bromine. The combustion of these vulcanizates results in the formation of bromine radicals that show a great reactivity in relation to $\mathrm{H}$ and $\mathrm{OH}$ radicals, derived from the thermal decomposition of elastomer. The reactions between $\mathrm{Br}$ radicals and $\mathrm{H}$ and $\mathrm{OH}$ radicals, proceeding in flame, result in the release of hydrogen bromide and water that evaporates, and decreases the energy balance of combustion [23]. Water vapor as non-flammable gas impedes the diffusion of oxygen to the combustion zone, which considerably reduces the yield of free radical processes. The reduction in the yield of free radical reactions proceeding in flame decreases the amount of heat emitted during combustion as indicated by the flammability test results of nanocomposites, obtained by the method of cone calorimetry (THR, HRR, Table 5). In this connection, the amount of heat passing from flame to the solid phase of the material under combustion is considerably lower, which can cause its selfextinguishing (NSHBr15, Table 4). The review of the relevant literature indicates that brominated flame-retardant compounds are effective when the bromine content in the composite exceeds $7 \%$ by wt [24]. Our the test results show that the bromine content in the modified $\mathrm{H}$ amounts to $10.21 \%$ by wt. When the filler is incorporated into the elastomer matrix in a quantity of $5 \%$ by wt, the bromine compounds show their effectiveness at a concentration as low as $0.51 \%$ by wt.

In the case of NBR nanocomposites containing the $\mathrm{H}$ modified with halogen compounds, their sample did not ignite in air under the influence of a $5 \mathrm{~s}$ time of gas burner flame. Their ignition occurred $20 \mathrm{~s}$ after applying the source of flame. Sample NSHBr15 underwent self-extinguishing 
(Table 4). The SBR sulfur vulcanizates containing the $\mathrm{H}$ modified with bromine, and sample SSHI15 containing $15 \mathrm{phr}$ of the filler modified with iodine, also required at least $20 \mathrm{~s}$ for ignition.

The ignition temperature of the cross-linked vulcanizates is significantly higher under the influence of the modified nanofiller. The lowest ignition temperature $(T z)$ is shown by the nanocomposites filled with the $\mathrm{H}$ modified with boric acid. The combustion time in the air $\left(t_{\mathrm{s}}\right)$ of these materials is also the shortest, especially in the case of NBR sulfur vulcanizates (Table 4).

Under the influence of the modified filler, the maximal HRR $\left(\mathrm{HRR}_{\max }\right)$ during the combustion of all the material obtained is decreased regardless of the determination method of this parameter (Tables 4, 5). The value of $\mathrm{HRR}_{\max }$ depends on the filler content in the rubber. Hence, the reduction in the flammability of vulcanizates determined with this parameter results from the barrier properties of the filler used. Worthy of noticing is the temperature of $\mathrm{HRR}_{\max }\left(\mathrm{TRR}_{\max }\right)$ during the combustion of polymeric materials, which rises under the influence of the modified filler when compared to the reference samples (Table 4).

Considering the flammability of polymers, a significant piece of information comes from their HR, in regards to specific heat referred to a unit of sample mass. It is defined as the energy required for increasing the temperature of the body mass unit by a temperature unit, thus, it expresses a heat absorption capability of the given material [25]. The flammability test results show that most nanocomposites obtained have increased HR in relation to reference samples (Table 4). The highest value of HR is shown by NBR vulcanizates containing the lowest content of modified $\mathrm{H}$ (NSHI5, NSHBr5, NSHK5).

The results obtained by thermal analysis $(\mathrm{d} m / \mathrm{d} t, P w$, $P_{800}$, Table 3) have shown that the residue after the combustion of polymeric materials containing modified $\mathrm{H}$ was increased (Table 4). However, under the influence of the fillers, the oxygen consumption during the combustion of the vulcanizates filled with modified $\mathrm{H}$, is increased (Table 3). The comparative analysis of test results obtained by the method of cone calorimetry (Table 4) leads to a conclusion that the use of modified filler contributes to the decrease in the fire hazard of the investigated vulcanizates, which was determined by recorded parameters, especially the THR, HRR, HRR ${ }_{\max }$ and average MLR. The TTI of the nanocomposites (NNH5, NSH5, SNH5 and SSH5, Table 5) considerably increased compared to reference samples.

The greatest effectiveness in respect of parameter TTI is shown by the filler modified with an aqueous solution of boric acid (Table 5). The $\mathrm{H}$ modification does not adversely affect its structure, as is shown on SEM photographs (Fig. 1a, b). On the image, it is easy to recognize not-changed nanotubes.

\section{Conclusions}

The studies of modified $\mathrm{H}$, as a nanofiller of rubber, has brought few interesting results valuable from the point of view of thermal properties and flammability of elastomer nanocomposites.

Regardless of the chemical structure of the investigated elastomers and their spatial network structure, the modified $\mathrm{H}$ contributes to a considerable decrease in the destruction rate of the nanocomposites under thermo-oxidative conditions, and to increase in their residue after combustion. This is a significant reason for the reduction in the flammability of the tested vulcanizate. Some of them fail to ignite in air under the influence of flame action for $5 \mathrm{~s}$. In addition, the modified $\mathrm{H}$ makes possible to obtain selfextinguishing elastomeric materials.

The analysis of the parameter values obtained by the method of cone calorimetry has confirmed that the most NBR and SBR vulcanizates filled with modified $\mathrm{H}$ are characterized by the reduced fire hazard.

Open Access This article is distributed under the terms of the Creative Commons Attribution License which permits any use, distribution, and reproduction in any medium, provided the original author(s) and the source are credited.

\section{References}

1. Janowska G. The influence of flame retardants on the thermal stability of cis-1,4-polyisoprene. J Therm Anal Calorim. 1998;53:309-16.

2. Rybiński P, Janowska G. Effect of flame retardants on thermal stability and flammability of cured nitrile rubber. Polimery. 2009;11-12(54):833-9.

3. Rooj S, Das A, Thakur V, Mahaling RN, Bhowmick AK, Heinrich G. Preparation and properties of natural nanocomposites based on natural rubber and naturally occuring halloysite nanotubes. Mater Des. 2010;31:2151-6.

4. Du M, Guo B, Jia D. Thermal stability and flame retardant effects of halloysite nanotubes on poly(propylene). Eur Polym J. 2006;42:1362-9.

5. Handge UA, Hedicke-Höchstötter K, Altstädt V. Composites of polyamide 6 and silicate nanotubes of the mineral halloysite: influence of molecular weight on thermal, mechanical and rheological properties. Polymer. 2010;51:2690-9.

6. Horvath E, Kristof J, Kuroli R, Mako E, Khunova V. Study of urea intercalation into halloysite by thermoanalytical and spectroscopic techniques. J Therm Anal Calorim. 2011;105:53-9.

7. Guo B, Lei Y, Chen F, Liu X, Du M, Jia B. Styrene-butadiene rubber/halloysite nanotubes nanocomposites modified by methacrylic acid. Appl Surf Sci. 2008;255:2715-22.

8. Ismail H, Pasbakhsh P, Ahmad Fauzi MN, Abu Bakar A. Morphologicla, thermal and tensile properties of halloysite nanotubes filled ethylene-propylene diene monomer (EPDM) nanocomposites. Polym Test. 2008;27:841-50.

9. Sheng F, Tang X-Z, Zhang S, Ding X, Zhong-Zhen Y, Qiu Z. Flame retardancy of polyamide 66 nanocomposites with thermally stable organoclay. Polym Adv Technol. 2012;23:137-42. 
10. Zhang W, Li X, Yang R. Flame retardancy mechanisms of phosphorous-containing polyhedral oligomeric silsesquioxane (DOPO-POSS) in polycarbonate/acrylonitrile-butadiene-styrene blends. Polym Adv Technol. 2012;23:588-95.

11. Rybiński P, Janowska G, Jóźwiak M, Pająk A. Thermal properties and flammability of nanocomposites based on diene rubbers and naturally occurring and activated halloysite nanotubes. J Therm Anal Calorim. 2012;107:1243-9.

12. Marney DCO, Yang W, Russell LJ, Shen SZ, Nguyen T, Yuan Q, Varley R, Li S. Phosphorous intercalation of halloysite nanotubes for enhanced fire properties of polyamide 6. Polym Adv Technol. 2012. doi:10.1002/pat3030.

13. Rybiński P, Janowska G, Jóźwiak M, Pająk A. Thermal stability and flammability of butadiene-styrene rubber nanocomposites. J Therm Anal Calorim. 2012;109:561-71.

14. Janowska G, Rybiński P, Kucharska-Jastrząbek A. Sposób wytwarzania materiału elastomerowego o ograniczonej palności i samowygaszającego się podczas spalania w powietrzu. Patent declaration No. P-391147.

15. Rybiński P, Janowska G, Kucharska-Jastrząbek A, Pająk A, Wójcik I, Wesołek D, Bujnowicz K. Flammability of vulcanizates of diene rubbers. J Therm Anal Calorim. 2012;102:1219-24.

16. Rooj S, Das A, Heinrich G. Tube-like natural halloysite/fluoroelastomer nanocomposites with simultaneous enhanced mechanical, dynamic mechanical and thermal properties. Eur Polym J. 2011;47:1746-55.
17. Mellouk S, Belhakem A, Marouf-Khelifa K, Schott J, Khelifa A. $\mathrm{Cu}$ (II) adsorption by halloysites intercalated with sodium acetate. J Colloid Interface Sci. 2011;360:716-24.

18. Janowska G, Kucharska-Jastrząbek A, Rybiński P. Flammability of diene rubbers. J Therm Anal Calorim. 2010;102:1043-9.

19. Marney DCO, Russell LJ, Wu DY, Nguyen T, Cramm D, Rigopoulos N, Wright N, Graves M. The suitability of halloysite nanotubes as fire retardant for nylon 6. Polym Degrad Stab. 2008;93:1971-8.

20. Joussein E, Petit S, Delvaux B. Behaviour of halloysite clay under formamide treatment. Appl Clay Sci. 2007;35:17-24.

21. Nicolini KP, Budziak Fukamachi CR, Wypych F, Mangrich AS. Dehydrated halloysite intercataed mechanochemically with urea. Thermal behaviour and structural aspects. J Colloid Interface Sci. 2009;338:474-9.

22. Cheng H, Liu Q, Yang J, Zhang J, Frost RL. Thermal analysis and infrared emission spectroscopic study of halloysite-potassium acetate intercalation compounds. Thermochim Acta. 2010;511:124-8.

23. Janowska G, Przygocki W, Włochowicz A. Palność polimerów i materiałów polimerowych. Warszawa: WNT; 2007.

24. Modorskij S. Thermal decomposition of organic polymers. New York: Intra-Science; 1964.

25. Boryniec S, Przygocki W. Procesy spalania polimerów. Polimery. 1999;44(10):656-65. 